emerging therapy for difficult nephrotic syndrome $[5,6]$. Rituximab allows such patients to discontinue steroid treatment and dramatically reduces the number of relapses. Rituximab can also induce remission in patients with intractable steroid-resistant nephrotic syndrome. Although more clinical experience is needed to establish a safe and effective mode of administration, such new molecular target therapies will improve the clinical course of childhood nephrotic syndrome in the future.

\section{REFERENCES}

1. Sinha A, Hari P, Sharma PK, Gulati A, Kalaivani M, Mantan M, et al. Disease Course in Steroid Sensitive Nephrotic Syndrome. Indian Pediatr. 2012;49:881-7 .

2. Improving Global Outcomes (KDIGO) Glomerulonephritis Work Group. KDIGO Clinical
Practice Guideline for Glomerulonephritis. Kidney Inter. 2012; 2: 139-274.

3. Gipson DS, Massengill SF, Yao L, Nagaraj S, Smoyer WE, Mahan JD, et al. Management of childhood onset nephrotic syndrome. Pediatrics. 2009;124: 747-57.

4. Hodson EM, Willis NS, Craig JC. Corticosteroid therapy for nephrotic syndrome in children. Cochrane Database Syst Rev. 2007; 17:CD001533.

5. Gulati A, Sinha A, Jordan SC, Hari P, Dinda AK, Sharma $\mathrm{S}$, et al. Efficacy and safety of treatment with rituximab for difficult steroid-resistant and dependent nephrotic syndrome: multicentric report. Clin J Am Soc Nephrol. 2010;5:2207-12.

6. Ito S, Kamei K, Ogura M, Sato M, Fujimaru T, Ishikawa T, et al. Maintenance therapy with mycophenolate mofetil after rituximab in pediatric patients with steroid-dependent nephrotic syndrome. Pediatr Nephrol. 2011; 26:1823-8.

\title{
Risk Factors for Mortality in Children Hospitalized with Pneumonia
}

\author{
AK PATWARI \\ Department of Pediatrics, Hamdard Institute of Medical Science \& Research, New Delhi. \\ akpatwari@gmail.com
}

$\mathrm{P}$ neumonia continues to be one of the leading causes of mortality among children under five years of age despite effective vaccines and nutritional and environmental interventions. Pneumonia deaths in health facilities might appear as the 'tip of the iceberg' because most of the deaths are taking place even before these children reach a health facility. However, with improvement in referral services, an increasing proportion of pneumonia deaths are likely to happen in hospitals. Therefore, identification of risk factors of death in hospitalized children suffering from pneumonia is critical for optimal utilization of scarce resources for appropriate management and reduction of childhood mortality.

Significant independent predictors of mortality in children with pneumonia reported earlier by several prospective studies relate to host characteristics (age less than 1 year, lack of exclusive breastfeeding), severity of infection (severe roentgenogram changes, leukocytosis, bandemia), worsening of clinical condition, and hypoxemia (inability to feed, grunting, head nodding, respiratory rate $>70 /$ minute, severe chest indrawing, cyanosis), severe malnutrition (weight for age $\mathrm{Z}$ score $<-3$ ) and associated co-morbidities like diarrhea and HIV [1-4].

In this issue, Ramachandran, et al. [5] attempt to review the situation based on retrospective chart review of
4375 children over a period of 3 years. The case fatality rate (CFR) has been reported as $8.2 \%$ which is comparable to earlier published reports [1]. This study has identified need for assisted ventilation as the single independent risk factor for mortality in children with pneumonia diagnosed by radiological, clinical or clinical and radiological criteria. The results of this study have been primarily interpreted as comparison between 3 study groups, based on certain diagnostic criteria. No significant differences have been noted in the CFR among these study groups. Since it was a retrospective review no hypothesis was made for any expected differences between these groups. However, comparison of data from three different diagnostic/identification groups with studies using similar criteria would have been helpful.

Categorization of cases according to severity at the time of admission is critical to identify 'at risk' children for anticipating the clinical course and to be prepared to handle any complications. A study from Delhi [1] has demonstrated this important association of severity of illness with CFR ranging from $0-47 \%$ in children with pneumonia, severe pneumonia, and very severe pneumonia as per WHO classification. In the study by Ramachandran, et al. [5] 47-68\% of the children who died required assisted ventilation which is much higher than reported by others [2]. It is difficult to understand the 
practical importance of this association because the clinical course and pathway to death can not be visualized if the cases are not categorized based on severity of illness at the time of admission. In the absence of information regarding hospital course/worsening, appearance of 'danger signs', treatment failures and status of oxygen saturation, the need for intensive care and/or assisted ventilation appears to be a symptomatic progression of most of the severe cases. Identification of risk factors at the time of admission and during early clinical course is more useful to anticipate and guide specific action-oriented approaches to reduce burden of pneumonia mortality in hospitalized children.

Besides awareness regarding risk factors associated with adverse outcome of pneumonia, it is also critical to monitor sick children for clinical deterioration to prevent death. In a systematic review, the median prevalence of hypoxemia in WHO defined severe and very severe pneumonia was $13 \%$ [6]. Hypoxemia is associated with 25 fold increase in risk of death [7]. There is no doubt that detecting hypoxemia presents a challenge in resourcelimited health facilities. Since many studies have demonstrated a low predictive value of clinical signs of hypoxemia, pulse oximetry is the optimal approach to determine the need for and response to oxygen therapy [8]. Early detection of hypoxemia by pulse oximetry and effective treatment of hypoxemia by oxygen therapy is an important component of in-patient management of pneumonia.

Association of underlying congenital heart disease with pneumonia mortality reported between $7-12 \%$ within the groups [5] is comparable to other studies from India though much higher figures have been reported from China [2]. Presence of co-morbidities, in this study particularly diarrhea and HIV, has been reported as an important risk factor for severe pneumonia in areas with high prevalence of HIV [4]. These observations support a thorough clinical assessment at the time of admission to pick up underlying co-morbidities in order to provide optimum treatment for these specific conditions.

Weight for age $<-2 Z$ score has been significantly associated with mortality [5]. Pneumonia is more common and more likely to be fatal in children with severe malnutrition. These observations assume even greater importance because validity of WHO recommended clinical signs has been reported to be less sensitive as predictors of radiographic pneumonia in severely malnourished children [9]. Results of a study from Gambia [10] suggest that the lower limiting values of respiratory rates in malnourished children with pneumonia must be five breaths less per minute than the respiratory rates in well-nourished children.

Case fatality in children with pneumonia is associated with several factors including clinical condition of the child at the time of admission, quality of care and monitoring during hospital stay, and appropriate supportive care including oxygen therapy and ventilation. Recognizing children with pneumonia who are 'high risk group' after initial assessment and also identifying 'at higher risk' children during monitoring in a health facility is by itself an important intervention to reduce under-five mortality.

Funding: Nil; Competing interests: None stated.

\section{REFERENCES}

1. Sehgal V, Sethi GR, Sachdev HP, Satyanarayana L. Predictors of mortality in subjects hospitalized with acute lower respiratory tract infections. Indian Pediatr.1997;34:213-9.

2. Zhang Q, Guo Z, Bai Z, Macdonald NE. A 4 year prospective study to determine risk factors for severe community acquired pneumonia in children in southern China. Pediatr Pulmonol. 2012 Jul 6. doi: 10.1002/ ppul.22608. [Epub ahead of print].

3. Shann F, Barker J, Poore P. Clinical signs that predict death in children with severe pneumonia. Pediatr Infect Dis J. 1989;8:852-5.

4. Tiewsoh K, Lodha R, Pandey RM, Broor S, Kalaivani M, Kabra SK. Factors determining the outcome of children hospitalized with severe pneumonia. BMC Pediatrics. 2009;9:15.

5. Ramachandran $P$, Nedunchelian K, Vengatesan A, Suresh S. Risk factors for mortality in community acquired pneumonia among children aged 1-59 months admitted in a referred hospital. Indian Pediatr. 2012;48:889-95.

6. Subhi R, Adamson M, Campbell H, Weber M, Smith K, Duke $\mathrm{T}$. The prevalence of hypoxemia among ill children in developing countries: a systematic review. Lancet. 2009;9:219-27.

7. Djelantik IG, Gessner BD, Sutanto A, Steinhoff M, Linehan M, Moulton LH, et al. Case fatality proportions and predictive factors for mortality among children hospitalized with severe pneumonia in a rural developing country setting. J Trop Pediatr. 2003;49:327-32.

8. Graham SM, English M, Hazir T, Enarson P, Duke T. Challenges to improving case management of childhood pneumonia at health facilities in resource-limited settings. Bull World Health Organ. 2008;86:349-55.

9. Chisti MJ,Tebruegge M, La Vincente S, Graham SM, Duke $\mathrm{T}$. Pneumonia in severely malnourished children in developing countries- mortality risk, aetiology and validity of WHO clinical signs: a systematic review. Trop Med Int Health. 2009, 14:1173-89.

10. Falade AG, Tschappeler H, Greenwood BM, Mulholland EK. Use of simple clinical signs to predict pneumonia in young Gambian children: the influence of malnutrition. Bull World Health Organ. 1995;73:299-304. 